\title{
Erratum to: Attracting Minority Applicants to Malaysian Organizations: The Effect of Race Composition
}

\author{
Yin Lu Ng
}

Published online: 16 September 2011

(C) National Academy of Psychology (NAOP) India 2011

Erratum to: Psychol Stud (2011) 56:271-279

DOI 10.1007/s12646-011-0090-1

The original version of this article unfortunately contained an inadvertent mistake.

The volume and issue number on pages $273,275,277$ and 279 has been changed to 56 (2). The correct volume and issue number is 56 (3).

The Publisher apologizes for this error.

The online version of the original article can be found at http://dx.doi. org/10.1007/s12646-011-0090-1.

Y. L. $\mathrm{Ng}(\bowtie)$

Department of Psychology, HELP University College,

Wisma HELP, Jalan Dungun,

50490 Kuala Lumpur, Malaysia

e-mail: ngyl@help.edu.my 